\title{
An investigation on e-resource utilisation among university students in a developing country: A case of Great Zimbabwe University
}

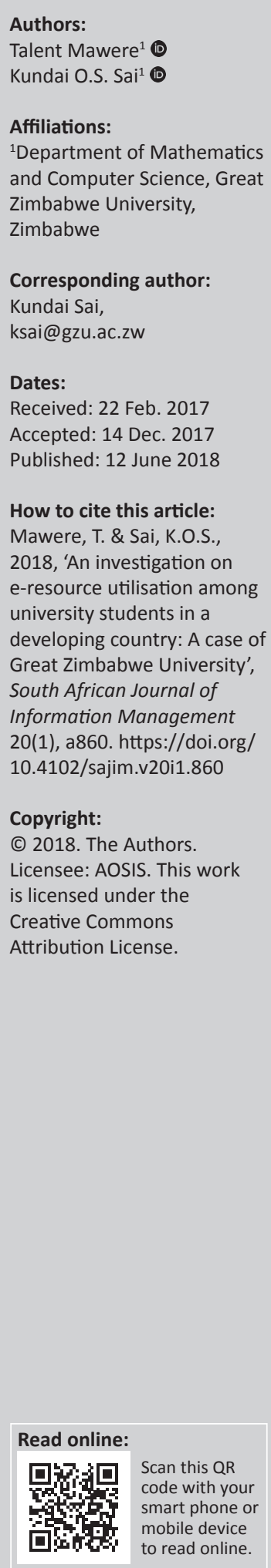

Background: Electronic libraries are the recent development in the ever-changing technological world today. Students nowadays have the ability to carry the library wherever they are, their Internet-enabled devices being the only requirement. Most universities worldwide have subscribed to various online databases and other e-resources as a way of availing resources to their students. To their credit, most institutions of higher learning in developing countries have not been left out in this stampede.

Objectives: The study aimed at investigating the adoption and utilisation of e-resources by students at a university in a developing country.

Method: The Technology Acceptance Model (TAM) model was used to conceptualise the study. A survey questionnaire was designed and distributed through social media platforms such as Facebook and WhatsApp. Quantitative data were analysed using the Statistical Package for the Social Sciences (SPSS). The Chi-squared test was used to test for casual relationships within the developed model. A thematic approach was used to analyse qualitative data.

Results: Despite the fact that many Zimbabwean academic institutions have made the facility of e-libraries top agenda in their strategic plans, the adoption rate among students is still very limited. This can be attributed to a myriad of facts, inter alia, poor marketing strategies, lack of resources among the students and exorbitant data charges by Internet Service Providers (ISPs).

Conclusion: This study has provided some basic insights in utilisation of e-resources in universities of developing countries. Despite the younger generation being described as digital natives, it is, quite evident that their uptake of technological innovations especially in education is quite poor. This research will assist both researchers and management of institutions of higher learning to provide and design amicable solutions to the problem of poor utilisation of e-resources as it highlights the major causes of poor utilisation in the developing country context.

\section{Introduction}

Electronic resources and databases are invaluable tools for studying, learning and researching. The rapid proliferation in the use of the Internet has facilitated the creation and use of these electronic resources. The traditional approach whereby a tutor was the only source of information is quickly becoming obsolete as information continues to migrate to the cloud. Students nowadays are thus more empowered and capacitated to not only learn more but also study at their own pace by accessing these resources. Electronic resources, such as e-journals and online databases, now have an edge over the traditional print-based media as they are most likely to contain current information, offer advanced search capabilities, greater flexibility in storage and enable access of information without time and location constraints.

At institutions of higher learning, students are often presented with challenging subjects, and without access to relevant information they might struggle to obtain deeper and broader understanding of the courses or subjects and learning in general. The availability of information in electronic format which facilitates easier indexing and searching thus simplifies students' lives in accessing relevant information. One major component of higher education is research and as such higher education must develop and instil research skills in order to produce qualified individuals, engaged in the lifelong pursuit of knowledge for personal and professional growth (Togia \& Tsigilis 2009). In addition, it is expected that an educator comfortable in using electronic resources may encourage his or her students to do the same, and thus contribute to their computer 
and information literacy (Togia \& Tsigilis 2009). For students in the Faculty of Education in particular, the ability to effectively utilise electronic information resources is a key issue because it assists in enhancing the quality of their teaching when they become professionals.

Quite a number of research on the use of e-resources have been conducted in developed countries, which include Appleton (2006), Rogers et al. (2011), Adams and Bonk (1995), Berzins and Hudson (2011) and Deng (2010), among others. However, developing countries are presented with significant challenges of their own, which might not apply in other countries, hence warranting and making this research relevant. Such challenges include, inter alia, cost of implementation, Internet connectivity challenges, shortage of technological devices such as computers, lack of trained personnel, lack of local online databases and limited bandwidth (Adeniran 2013; Chitanana, Makaza \& Madzima 2008; Legris, Inghamb \& Collerettec 2003; Mittal \& Bala 2013; Mosha \& Bea 2014; Okello-Obura 2010).

As institutions of higher learning in developing countries attempt to emulate world-class standards, they have not been left out in the drive to provide access to electronic databases so as to empower their students. In Zimbabwe, to their credit, institutions like Great Zimbabwe University (GZU) and Midlands State University, to name just a few, have managed to source such services despite challenges elaborated on above. With the growth in popularity of electronic resources, the traditional roles of libraries are gradually migrating from print documents to e-resources, where providing access to information is considered more important than owning it (Kumar 2009).

\section{What are e-resources?}

The term 'e-resources' an acronym used in reference to electronic resources or electronic information resources. These are collections of information in electronic or digital format that are accessed on an electronic device, such as a mobile phone, computer, etc. They are published resources in electronic versions or format such as encyclopaedias, pamphlets, e-books, e-journals, databases, etc. A number of authors have also provided their own definitions. Adams and Bonk (1995), Scan (2010), Moyo (2004), Liu (2006) and Nicholas et al. (2009) defined electronic resources as databases, books, journals, newspapers, magazines, archives, theses, conference papers, examination papers, government papers, research reports, scripts and monographs in an electronic format. Swain and Panda (2009a) regarded e-resources as reservoirs of information that may be milked through various electronic devices such as computers, smart phones, tablets, etc. 'They are fine grained and restructured and often stored within the cyberspace in a compact form'. The major advantage of e-resources is that they can be simultaneously accessed ubiquitously around the world by a great number of users. Nicholas et al. (2017) also concured that the use of electronic resources, such as search engines, was highly popular among early-career researchers irrespective of country, language and discipline. Appleton (2006) elucidates that changes in the traditional way of document delivery services, from print to electronic, have come about swiftly; hence, information services and libraries have transformed significantly so that they can deliver this new technology effectively to academics. The potential of digital and interactive experiences for students cannot be understated. It is necessary to provide quality e-resources to guarantee engaging experiences of multimodal texts to back up authentic teaching and learning needs. Also a diverse range of reading experiences are provided for students to support literacy and reading, access to a balanced range of resources for students and teacher (Okello-Obura 2010).

\section{Types of electronic resources available at Great Zimbabwe University}

Great Zimbabwe University is the highest institution of learning in the Masvingo Province, Zimbabwe. At the time of writing this article, the institution boasted of a population of over 13000 students housed across multiple campuses and an academic staff complement of over 350 individuals who constantly embark in research activities. The institution offers access to a wide range of e-resources for use by its stakeholders subscribed across different consortiums such as the Zimbabwe Universities Librarians Consortium (ZULC). The library is also a member of the International Federation of Library Associations and Institutions (IFLA), Electronic Information for Libraries (eIFL) and the International Network for the Availability of Scientific Publications (INASP). These organisations assist the university by providing subsidised access to e-resources, as well as capacity-building, staff development, networking facilities and participation in innovative library agenda settings. Being a member of these associations shows the university management's commitment in the provision of modernised information systems for availing reading materials for its stakeholders. Below are some brief descriptions of the types of electronic resources which are available through the university. These resources can be accessed via the university website under the 'library' link.

\section{Advanced Search engine}

The university provides a EBSCO federated search engine, which enables stakeholders to query the engine and search for journal articles or e-books. The engine sends queries among various libraries and provides links to possibly relevant results.

\section{Institutional repository}

The university provides a link to the research activities and publications undertaken by the academic staff. At the time of writing of this article, however, no content had been posted. 


\section{Online databases}

The institution subscribes to numerous online databases where stakeholders can access e-books, e-journals, encyclopaedia, e-reference tools, etc. These are individually subscribed or via various consortiums such as ZULC. Zimbabwe Universities Librarians Consortium provides facilities for member institutions to jointly contribute towards the cost of acquisition of online databases instead of each institution subscribing on its own to the service providers. The cost of subscription to databases is thus greatly reduced.

\section{Electronic past examination papers}

The library provides access to a variety of past examination papers.

Despite serious measures taken by institutions to provide e-resources to their stakeholders, usage reports from the various consortiums indicate that usage of e-resources in developing countries is still far below par. These statistics are nothing further than the truth for GZU as usage reports from one database, Emerald Insight, show that journal article downloads are very low, with only 2890, 6541 and 10345 articles downloaded in 2014, 2015 and 2016, respectively, at GZU (Consortia and deal usage report 2013-2016). The university enrolment during the same period was 9175, 13173 and 13807 students, respectively (GZU student records). Despite the seemingly increasing number of downloads, download ratio per student population which translates to $0.315,0.496$ and 0.749 articles per student per year indicates a stunted growth. This statistics are indicative that despite numerous electronic resources being available, effective usage of these resources among the student population is very limited, and this will be the subject of scrutiny in this article.

\section{Literature review}

Speedy advancement of information and communication technologies (ICTs) has revolutionised the way information and knowledge is handled, ultimately presenting societies with varied options of how they can easily access information. However, in emerging economies, there seem to be many hindrances to scholars acceding to the use of e-resources (Okello-Obura 2010). The majority of reviewed literature on e-resource utilisation highlighted the lack of technical support, lack of ICT gadgets, high data charges, poor ICT skills and limited access to e-resources as major barriers of its usage (Abubakar \& Adetimirin 2016; Adeniran 2013; Deng 2010; Millawithanachchi 2012). Most of the literature reviewed regarding the use of Internet resources for teaching and learning indicates user-centred barriers, which include lack of skills on how to use information resources, lack of appropriate reward for electronic scholarly communication, lack of consistent technical support and lack of time to search for information, lack of ICT equipment and the cost of acquiring, using and maintaining ICT resources that acted as barriers on the side of the university (Mosha \& Bea 2014; Swain \& Panda 2009a; Togia \& Tsigilis 2009).

Deng (2010) noted that the usage of electronic resources was not uncommon in a university environment because of the rapid advance of ICTs. The research showed that the usage of e-resources was much dependent on the user and the purposes of using these resources. The author identified awareness and quality of the available electronic resources as important factors that led to the effective and efficient use of electronic resources. The findings shed light on the usage of electronic resources and assist university libraries to better understand the perception and experience of users in using these resources, leading to more effective and efficient use of electronic resources.

Millawithanachchi (2012) explored the popularity and usage of e-resources among postgraduate students in universities. Factor analysis identified nine factors which are critical success factors (CSFs) on e-resources usage. Among the nine CSFs, postgraduates identified 'technology' as the most critical factor in using e-resources. Library support, information literacy, computer competency, usefulness and user attitudes are identified as other CSFs for using e-resources for their learning activities.

Adeniran (2013) also studied the factors determining the usage of e-resources by undergraduate students and revealed that the use of electronic resources had tremendous impact on the academic performance of the undergraduate students; however, there is a need for them to acquire more skills in the use of electronic resources.

Swain and Panda (2009a, 2009b) also noted that user-centric factors were not the only limiting factors for e-resources use and access. Limited budgets, which in turn affect subscription capacity, can create resentment among users as they might fail to access required stuff. Limited library hours and poor marketing campaigns were also considered as hindrances to e-resources usage by patrons.

\section{Theoretical framework}

The Technology Acceptance Model (TAM) (Davis 1989) assists in explaining the usage and adoption of technological innovations. It has been employed together with other theories, such as the theory of reasoned action (TRA) (Fishbein \& Ajzen 1974) and innovation diffusion theories (Rogers 2003) to explain the adoption of various technological innovations, such as mobile banking, e-learning and Internet banking (Huang, Schrank \& Dubinsky 2004; Khalifa \& Shen 2008; Mawere et al. 2014; Tsu Wei et al. 2009; Yang 2005).

The TAM model asserts that an individual's usage of innovations is determined by the behavioural intention, which, in turn, is determined by two beliefs: perceived usefulness and perceived ease of use. These two constructs were considered as the basis for the current study. However, 
the model was extended to take into account other constructs to make it more inclusive to all factors influencing the usage of e-resources. Factors hindering the use of e-resources were regarded as external factors. Below is an extended TAM model for modelling factors influencing e-resource usage derived from the literature.

The following hypotheses were proposed:

H1: This relates to perceived usefulness of e-resources:

H1: Lack of relevant e-resources available in the area of study has no effect on the perceived usefulness of e-resources.

$\mathrm{H} 2, \mathrm{H} 3, \mathrm{H} 4, \mathrm{H} 5, \mathrm{H} 6$ and H7: These all relate to perceived ease of use of e-resources:

H2: Lack of training and support staff has no effect on perceived ease of use of e-resources.

H3: Lack of technical know-how has no effect on perceived ease of use of e-resources.
H4: Lack of assistance from library staff has no effect on perceived ease of use of e-resources.

H5: Difficulty of access to e-resource has no effect on perceived ease of use of e-resources.

H6: Inaccessibility of 'available' e-resources has no effect on perceived ease of use of e-resources.

H7: Limited access to electronic resources has no effect on perceived ease of use of e-resources.

H8, H9, H10 and H11: These all relate to external factors affecting the use of e-resources:

H8: Technological constraints do not hinder the intention to use e-resources.

H9: Exorbitant data charges have no effect on the intention to use e-resources.

H10: Inconvenient library hours do not affect students' intention to use e-resources.

H11: Unavailability of physical libraries and resources has no effect on students' intention to use e-resources.

Figure 1 illustrates the research model.

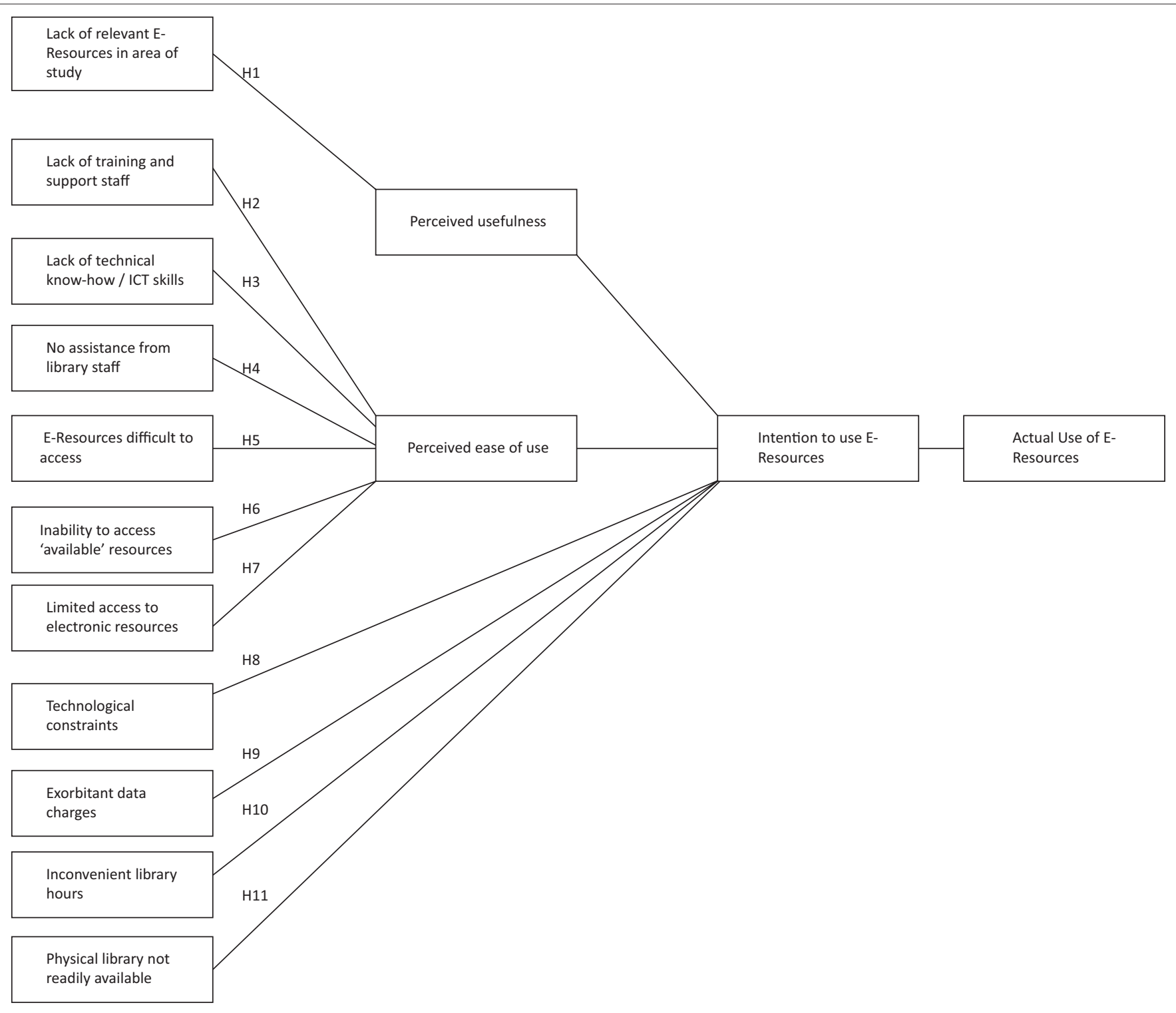

FIGURE 1: E-resource utilisation model derived from the Technology Acceptance Model. 


\section{Methodology}

A survey research method was adopted because it was considered more appropriate for this type of study. Data were collected through an online questionnaire. The total population was 13500 registered students at the GZU. A sample size of 576 students from different faculties within the university was used for the study. Of the sample, 213 were from the Faculty of Education, 149 from the Faculty of Social Sciences, 149 from the Faculty of Arts, 43 from the Faculty of Commerce and 22 from the Faculty of Science. These were calculated based on proportions of each faculty's total student population. The population sample size was calculated using the survey monkey sample size calculator (https:/ / www.surveymonkey.co.uk/mp/sample-sizecalculator/) at a $95 \%$ confidence level and a margin of error of $4 \%$. The resulting sample was a purely stratified random one as respondents were grouped according to faculties and selected randomly among the student population at GZU. The data in this article were collected from an online survey, using survey monkey, conducted between 01 August and 07 November 2016. The link to the survey questionnaire was posted on social media platforms such as Facebook and WhatsApp.

The questionnaire was designed to collect data on students' level of awareness of the availability, utilisation, purpose of use, perceived value and problems encountered in their use of e-resources. The questionnaire had both closed- and openended questions. Both the content and face validity of the questionnaire were established by giving the questionnaire to Computer Science and Statistics lecturers at the university to comment on its validity.

Interviews with the assistant librarian and the library e-resource focal person were arranged to clarify certain issues raised in the questionnaire. The results from these form most of the discussion on e-resources at the institution presented earlier.
Advanced statistical methods were used to identify the significant influencing factors and also causal pathways. Qualitative data were analysed using thematic analysis methods. The study identified and recommended possible intervention strategies through which universities in developing countries can increase the usage of electronic resources among their students population.

\section{Data presentation and analysis}

A total of 95 respondents responded (probably an indicator of students' uncomfortability in using technology), representing a $16.5 \%$ response rate of which $45.3 \%$ were males and $54.7 \%$ females. The majority of the respondents were from the Faculty of Social Sciences (78.9\%), with Science, Commerce and Education represented by $14.7 \%$, $3.2 \%$ and $3.2 \%$, respectively. Most of the respondents were aged between 18 and 24 years (84.2\%), with $13.7 \%$ being in the 25-34 years age group while only $2.1 \%$ of the respondents were aged over 35 years. In terms of level of study, most of the respondents were in their second year of study $(84.2 \%)$, while the rest were distributed evenly across levels 1,3 or 4 .

Chi-squared test at a 5\% level of significance was used to analyse the significance of the various factors which influence the use of electronic resources. The results are presented in Table 1 and explained as follows.

For H1, the calculated Pearson Chi-square value (16.040) is greater than the Chi-square critical value (15.5); hence, H1 is rejected. This means that there is a statistically significant relationship between the unavailability of relevant e-resources in areas of study and the perceived usefulness of e-resources. The null hypotheses $\mathrm{H} 2-\mathrm{H} 7$ are also rejected as the calculated Pearson Chi-square values are greater than the Chi-square critical values. Thus, we can conclude that the lack of training and support staff, lack of technical know-how, lack of

TABLE 1: Chi-squared analysis of hypothesis.

\begin{tabular}{|c|c|c|c|c|}
\hline List of hypothesis & Pearson Chi-square & Df & Chi-square critical value & $\begin{array}{l}\text { Decision (@ } 5 \% \text { level of } \\
\text { significance reject H0 if } X^{2} \\
\text { calculated }>X^{2} \text { critical) }\end{array}$ \\
\hline $\begin{array}{l}\text { H1: Lack of relevant e-resources availability in area of study has } \\
\text { no effect on perceived usefulness of e-resources. }\end{array}$ & 16.040 & 8 & 15.5 & Reject $\mathrm{H} 1$ \\
\hline $\begin{array}{l}\text { H2: Lack of training and support staff has no effect on perceived } \\
\text { ease of use of e-resources. }\end{array}$ & 22.878 & 12 & 21.0 & Reject $\mathrm{H} 2$ \\
\hline $\begin{array}{l}\text { H3: Lack of technical know-how has no effect on perceived ease } \\
\text { of use of e-resources. }\end{array}$ & 23.576 & 12 & 21.0 & Reject H3 \\
\hline $\begin{array}{l}\text { H4: Lack of assistance from library staff has no effect on } \\
\text { perceived ease of use of e-resources. }\end{array}$ & 25.357 & 12 & 21.0 & Reject $\mathrm{H} 4$ \\
\hline $\begin{array}{l}\text { H5: Difficulty of access to e-resource has no effect on perceived } \\
\text { ease of use of e-resources. }\end{array}$ & 22.934 & 12 & 21.0 & Reject H5 \\
\hline $\begin{array}{l}\text { H6: Inaccessibility of 'available' e-resources has no effect on } \\
\text { perceived ease of use of e-resources. }\end{array}$ & 23.192 & 12 & 21.0 & Reject H6 \\
\hline $\begin{array}{l}\text { H7: Limited access to electronic resources has no effect on } \\
\text { perceived ease of use of e-resources. }\end{array}$ & 24.873 & 12 & 21.0 & Reject H7 \\
\hline $\begin{array}{l}\text { H8: Technological constraints do not hinder the intention to use } \\
\text { e-resources. }\end{array}$ & 13.624 & 8 & 15.5 & Accept H8 \\
\hline $\begin{array}{l}\text { H9: Exorbitant data charges have no effect on the intention to } \\
\text { use e-resources. }\end{array}$ & 18.342 & 8 & 15.5 & Reject H9 \\
\hline $\begin{array}{l}\text { H10: Inconvenient library hours do not affect students' intention } \\
\text { to use e-resources. }\end{array}$ & 13.756 & 6 & 12.6 & Reject $\mathrm{H} 10$ \\
\hline $\begin{array}{l}\text { H11: Unavailability of physical library and resources has no effect } \\
\text { on students' intention to use e-resources. }\end{array}$ & 14.365 & 6 & 12.6 & Reject H11 \\
\hline
\end{tabular}


assistance from library staff, difficulty of access to e-resources, inaccessibility of 'available' e-resources and limited access to electronic resources are factors that directly affect the perceived ease of use of e-resources.

For H8 the calculated Pearson Chi-square value (13.624) is less than the Chi-square critical value (15.5); hence, the null hypothesis is accepted. This means that there is no statistically significant relationship between technological constraints and the intention to use e-resources. The above conclusion can be attributed to the university's 'Bring Your Own Device' (BYOD) policy that allows students and staff to use their own electronic gadgets to access the electronic resources. However, the null hypotheses $\mathrm{H} 9-\mathrm{H} 11$ are rejected as the calculated Pearson Chi-square values are greater than the Chi-square critical values. As a result, we can conclude that exorbitant data charges, inconvenient library hours and the unavailability of physical library and resources are factors that drive the students' intention to use electronic resources. These results are consistent with that of previous studies (Adeniran 2013; Deng 2010; Mittal \& Bala 2013; Mosha \& Bea 2014). However, most of the respondents in this study were students from the Social Science disciplines; hence, the results might not be true representative of the population. There was also a need to include qualitative analysis in order to validate the results.

The library representatives provided answers to questions on the type of e-resources available and measures that were taken to improve the accessibility and visibility of these e-resources among the university's stakeholders.

\section{Recommendations}

The findings of this research indicate that despite frantic efforts by the university to avail e-resources, there is poor utilisation. The major attributor according to data analysis is the lack of awareness and ignorance of the facilities among students. Universities should therefore conduct awareness campaigns on the availability of these facilities and the benefits that students might derive from their use. This should be done to ensure that all the stakeholders have knowledge of e-resources existence within their institutions. The library department has attempted to conduct awareness programmes for both students and staff; however, the timing of these was observed to be poor as most of the students were on mid-semester break and most staff were busy marking assignments. An appropriate period such as the beginning of a semester should be selected to conduct these awareness campaigns, and they should be done in conducive environments. There is a need to increase the level of marketing of e-resources among the students by the university (e.g. hosting e-literacy events fortnightly).

Unavailability of relevant e-resources in areas of study was also cited as a hindrance to e-resources utilisation. The university should thus increase the scope of journals by subscribing to those journals that are not included in the ZULC list (e.g. American Psychological Association (APA) and Institute of Electrical and Electronics Engineers (IEEE) journals) in order to cater for specialised areas in the Social and Natural Sciences. Partnerships with local publishing companies such as Zimbabwe Publishing House (ZPH) and Longman Pvt Ltd can also be sought so as to provide local content which is not readily available in international journals.

Poor Internet connectivity and low bandwidth are other hindrances to e-resource utilisation as cited by students. Institutions should ensure that they subscribe to appropriate bandwidth packages which are in commensurate with the number of students enrolled at the particular institution. Information Technology (IT) directors should ensure that what they are paying for in terms of data usage tally with actual usage. There are often conflicting views from data service providers on what they claim to have provided and what users claim to have used. Data usage monitoring tools should be similar to those that service providers use to allow for uniformity and consistency. There is also a need to increase the number of both physical and wireless Internet access points in the university campus and in the students' halls of residence to negotiate the need of cellular data on the students' part as exorbitant data prices were cited as a contributory factor of poor utilisation.

In this research, no significant relationship was found between technological constraints and the intention to use e-resources. This had been mainly attributed to the university's BYOD policy. However, not all students have the financial capability to buy their own devices. Hence, it is recommended that the institution should provide IT resources which correspond to the number of students enrolled. There is a need for the university to provide enough networked computers in the libraries and laboratories in order to provide access to a greater number of students. Currently the student to computer sharing ratio is quite high and this situation needs to be dealt with swiftly so as to emulate world-class standards. It is quite commendable that most institutions are offering an introductory course in computers. However, as long as the student to computer sharing ratio is high, not all students will be able to derive many benefits from this initiative. This is so because they might not have enough time to cover all practical components of the course.

Most e-resources offered by the institution are only available within the university's network infrastructure. This means students who are not on the campus cannot access these resources. The university should also consider creating a Virtual Private Network (VPN) link in order to enable students to have access to the electronic resources from outside the university network.

Lastly, there are some e-resources that are said to be available on the university's website. However, trying to access such resources, one is often redirected to a window where one is 
suppose to subscribe in order for one to access the resources (e.g. Google books). Such cases normally lead to resentment and distrust in the library services among students. It is recommended that the library department should undertake a comprehensive analysis of the resources it offers and take down dead links.

\section{Conclusion}

This study has provided some basic insights on e-resource utilisation in the context of a university in a developing country. Despite the younger generation being described as digital natives, it is quite evident that their uptake of technological innovations especially in education is quite poor. Poor utilisation of e-resources cannot however be solely attributed to ignorance on the part of the students alone but to other external factors. Implementing the recommendations alluded to earlier is likely to see improved utilisation of electronic resources. A research gap still exists within the same area on the level of utilisation of e-resources among academics in developing countries. There is also a need to study the feasibility of an Open Access Institutional Repository where researchers within and outside the institution can submit their research articles.

\section{Acknowledgements}

The authors thank the Great Zimbabwe University authorities, library staff and students for their support.

\section{Competing interests}

The authors declare that they have no financial or personal relationships that may have inappropriately influenced them in writing this article.

\section{Authors' contributions}

T.M. was the project leader and participated in hypothesis design, research design, data collection and analysis, and writing of the manuscript. K.O.S.S. participated in hypothesis design, review of the literature, data collection, data codification and analysis, and manuscript editing and formatting.

\section{References}

Abubakar, D. \& Adetimirin, A., 2016, 'Postgraduate students' use of e-resources in Nigerian university libraries: What is the influence of user education?', Journal of Information Science Theory and Practice 4(3), 43-56. https://doi.org/10.1633/ jistap.2016.4.3.3

Adams, J.A. \& Bonk, S.C., 1995, 'Electronic information technologies and resources: Use by university faculty and faculty preferences for related library services', College \& Research Libraries 56, 119-131. https://doi.org/10.5860/crl_56_02_119

Adeniran, P., 2013, 'Usage of electronic resources by undergraduates at the Redeemer's University, Nigeria', International Journal of Library and Information Science 5(10), 319-324.
Appleton, L., 2006, 'Perceptions of electronic library resources in further education', TheElectronicLibrary24(5),619-634.https://doi.org/10.1108/02640470610707231

Berzins, K. \& Hudson, A., 2011, The use of E-resources. A snapshot of e-resource use among Linking London LLN partner institutions, LLN, London.

Chitanana, L., Makaza, D. \& Madzima, K., 2008, 'The current state of e-learning at universities in Zimbabwe: Opportunities and challenges', International Journal of Education and Development Using ICT 4(2), 5-15.

Davis, F.D., 1989, 'Perceived usefulness, perceived ease of use, and user acceptance of information technology', MIS Quarterly 13(3), 319-340. https://doi.org/10.2307/ 249008

Deng, H., 2010, 'Emerging patterns and trends in utilizing electronic resources in a higher education environment', New Library World 111(3/4), 87-103. https://doi. org/10.1108/03074801011027600

Fishbein, M. \& Ajzen, I., 1974, Belief, attitude, intention and behaviour: An introduction of theory and research, Addison-Wesley, Reading, MA.

Huang, W.Y., Schrank, H. \& Dubinsky, A.J., 2004, 'Effect of brand name on consumers' risk perceptions of online shopping', Journal of Consumer Behavior 4(1), 40-50. https://doi.org/10.1002/cb.156

Khalifa, M. \& Shen, K.N., 2008, 'Explaining the adoption of transactional B2C mobile commerce', Journal of Enterprise Information Management 22(2), 110-124. https://doi.org/10.1108/17410390810851372

Kumar, A., 2009, 'Use and usage of electronic resources in business schools in India: FIIB', in ICAL, Delhi, India, August 5-8, 2009, pp. 573-578.

Legris, P., Inghamb, J. \& Collerettec, P., 2003, 'Why do people use information technology? A critical review of the technology acceptance model', Information \& Management 40, 191-204. https://doi.org/10.1016/S0378-7206(01)00143-4

Liu, Z., 2006, 'Print vs. electronic resources: A study of user perceptions, preferences, and use', Information Processing and Management 42, 583-592. https://doi. org $/ 10.1016 /$ j.ipm.2004.12.002

Mawere, T., Denhere, P., Manjeese, C. \& Sai, K.O., 2014, 'Towards a mobile banking adoption model for the Zimbabwean market', EXCEL International Journal of Multidisciplinary Management Studies 4(8), 34-44.

Millawithanachchi, U.S., 2012, 'Electronic resources usage by postgraduates at the University of Colombo: Identifying the critical success factors', Annals of Library and Information Studies 59, 53-63.

Mittal, P. \& Bala, M., 2013, 'Use of e-resources in universities', International Journa of Innovative Research in Computer and Communication Engineering 1(6), 1360-1361

Mosha, G. \& Bea, G., 2014, 'Barriers of using internet resources in higher learning institutions: A case of Mzumbe University in Morogoro Region in Tanzania', Information and Knowledge Management 4(8), 86-97.

Moyo, L.M., 2004, 'Electronic libraries and the emergence of new service paradigms', The Electronic Library 22(3), 220-230. https://doi.org/10.1108/02640470410541615

Nicholas, D., Boukacem-Zeghmouri, C., Rodríguez-Bravo, B., Xu, J., Watkinson, A., Abrizah, A. et al., 2017, 'Where and how early career researchers find scholarly information', Learned Publishing 30(1), 19-29.

Nicholas, D., Huntington, P., Jamali, H.R., Rowlands, I. \& Fieldhouse, M., 2009, 'Student digital information-seeking behaviour in context', Journal of Documentation 65(1), 106-132. https://doi.org/10.1108/00220410910926149

Okello-Obura, C., 2010, 'Assessment of the problems LIS postgraduate students face in accessing e-resources in Makerere University, Uganda', Collection Building 29(3), 98-105. https://doi.org/10.1108/01604951011060385

Rogers, E., 2003, Diffusion of innovations, The Free Press, New York.

Rogers, J., Usher, A. \& Kaznowska, E., 2011, The state of e-learning in Canadian universities: If students are digital natives, why don't they like e-learning? Toronto, $\mathrm{ON}$ : Higher Education Strategy Associates Intelligence.

Scan, 2010, 'E-resources: A taster of possibilities and issues', Scan 29(4), 30-43.

Swain, D. \& Panda, K., 2009a, 'Use of electronic resources in business school libraries of an Indian state: A study of librarians' opinion', The Electronic Library 27(1), 74-85. https://doi.org/10.1108/02640470910934605

Swain, D. \& Panda, K., 2009b, 'Use of electronic resources in business school libraries of an Indian state: A study', Collection Building 23(3), 108-116. https://doi. org/10.1108/01604950910971134

Togia, A. \& Tsigilis, N., 2009, 'Awareness and use of electronic information resources by education graduate students: Preliminary results from the Aristotle University of Thessaloniki', in Qualitative and quantitative methods in libraries (QQML) International Conference, Chania, Crete, Greece, May 26-29, 2009, pp. 464-471.

Tsu Wei, T., Marthandan, G., Yee-Loong Chong, A., Ooi, K.B. \& Arumugam, S., 2009, 'What drives Malaysian m-commerce adoption? An empirical analysis', Industria Management \& Data Systems 109(3), 370-388. https://doi.org/10.1108/026355 70910939399

Yang, J., 2005, 'Knowledge integration and innovation: Securing new product advantage in high technology industry', Journal of High Technology Management Research 1(16), 121-135. https://doi.org/10.1016/j.hitech.2005.06.007 